\title{
RACISMO RECREATIVO E INJÚRIA RACIAL: UMA ANÁLISE JURISPRUDENCIAL DO ANIMUS JOCANDI
}

\section{RECREATIONAL RACISM AND RACIAL INJURY: A JURISPRUDENTIAL ANALYSIS OF ANIMUS JOCANDI}

Beatriz Ferreira Figueiredo Maria José Amorim da Cruz

\begin{abstract}
RESUMO: O presente trabalho analisou, por meio de revisão bibliográfica, a inércia do Poder Judiciário brasileiro diante de ofensas racistas proferidas em tom humorístico, denominadas como racismo recreativo, cuja tipificação analisada encontra-se no delito de injúria racial no artigo 140, §3º do Código Penal. Destarte, o texto faz um percurso histórico entre as teorias raciais, apresentando desde o racismo científico até o chamado racismo cordial, a fim de explanar a tese do racismo recreativo, formulada por Adilson Moreira. Em seguida, é apresentada as diversas posições doutrinárias brasileiras acerca da injúria racial, apresentando, assim, a maneira pela qual é ensinada nos manuais de direito este delito. Por fim, é constatada, por meio de pesquisa na jurisprudência, a tendência dos tribunais brasileiros em optar pela absolvição em face do animus jocandi, provocando a impunidade de uma das modalidades do racismo no Brasil.
\end{abstract}

Palavras-chave: Racismo Recreativo. Jurisprudência. Injúria Racial. Animus jocandi.

\begin{abstract}
The present work analyzed, through bibliographic review, the inertia of the Brazilian Judiciary in the face of racist offenses rendered in a humorous tone, called recreational racism, whose typification is found in the offense of racial injury in article $140, \S 3^{\circ}$ of Penal Code. In this way, the text makes a historical journey between racial theories, presenting from scientific racism to the so-called cordial racism, in order to explain the thesis of recreational racism, formulated by Adilson Moreira. Then, the various Brazilian doctrinal positions on racial injury are presented, thus presenting the way in which this crime is taught in the law manuals. Finally, it is verified, through research in the jurisprudence, the tendency of Brazilian courts to opt for absolution in the face of animus jocandi, causing impunity for one of the modalities of racism in Brazil.
\end{abstract}

Keywords: Recreational Racism. Jurisprudence. Racial Injury. Animus jocandi.

\section{INTRODUÇÃO}

O objetivo deste trabalho é apresentar a atuação do Poder Judiciário diante do racismo recreativo, bem como a visão da doutrina penalista brasileira acerca da injúria racial, delito previsto no art. $140, \S 3^{\circ}$ do Código Penal, apontando a dificuldade dos magistrados e pesquisadores do direito em reconhecer práticas 
discriminatórias em tom humorístico como hábitos danosos e passíveis de sanção estatal.

As relações sociais no Brasil foram historicamente construídas a partir do processo de colonização portuguesa. Desse modo, a exploração dos povos nativos e africanos por parte dos colonizadores delimitou as estruturas sobre as quais esta sociedade seria formada e seus reflexos podem ser visíveis até a contemporaneidade. Neste trabalho serão analisadas, em específico, as consequências trazidas à população afrodescendente. Esta, mesmo após a abolição da escravidão, subsistiu de maneira marginalizada, tendo em vista que a Lei Áurea não incluía políticas públicas para a inserção igualitária dessa comunidade no meio social como faziam outras propostas do movimento abolicionista que foram rejeitadas, exemplo disso é o projeto de reforma agrária de André Rebouças, engenheiro negro que propôs distribuir propriedades para exescravos terem meios de produção e sobrevivência.

Além disso, é importante observar que o racismo ou a injúria racial quando praticadas abertamente sofrem um grau de reprovação maior da sociedade, entretanto quando se está camuflado pelo humor, a revolta social se torna bem menos expressiva. O sorriso diante de uma piada discriminatória revela um racismo encoberto e mal resolvido dos brasileiros, essa característica coaduna com o mito da democracia racial, pois historicamente tem-se uma tentativa de apagar todo o passado de exclusão racial e implantar a ideia de pacificidade das raças e orgulho da mestiçagem.

aspectos latentes no comportamento de brasileiros que não se consideram racistas, mas expressam seu racismo através de risos e relatos de piadas racistas, quando reunidos num espaço de lazer. O que é mais estranho é que esse tipo de comportamento racista não interfere na sua inatacável reputação de democratas raciais. (Dahia, 2010, p. 15)

Para a construção desse trabalho utilizou-se do método qualitativo, com uma pesquisa bibliográfica a partir de doutrinas de direito, a fim compreender o tipo da injúria racial, artigos científicos e livros das ciências sociais para discutir a evolução dos conceitos de racismo, dos quais a principal obra para o presente estudo é "Racismo Recreativo" do jurista Adilson Moreira. Ademais, realizou-se também uma pesquisa no site JusBrasil (site este que recolhe inúmeros julgados pelo Brasil e divulga-os na íntegra, dando ao leitor a opção por ler o texto também diretamente no site do tribunal do qual foi retirado o documento) a respeito do número de decisões jurisprudenciais envolvendo as palavras-chaves "injúria racial" e "piadas", com a finalidade de analisar o tratamento jurisprudencial do animus jocandi nessa espécie de crime.

\section{A EVOLUÇÃO HISTÓRICA DO RACISMO NO BRASIL}

Após anos de exploração de africanos forçosamente expatriados de sua terra, em 1888 o Brasil aboliu a escravidão. Todavia, ainda assim era notório que não havia real interesse da elite em promover mudança nos papéis hierárquicos que regiam o país, a classe dominante branca precisava manter seu status através da exclusão dos negros. Não sendo mais a escravidão um meio de dominação válido, foi preciso encontrar novos métodos de preservação da desigualdade racial que privilegiava a concentração de poder nas 
mãos de pessoas brancas, pois o racismo se adequa ao contexto sociocultural de cada lugar e período, modificando seus instrumentos, mas mantendo o objetivo (MOREIRA, 2019). Assim, a ciência foi utilizada a serviço do projeto racial como meio de justificativa para o tratamento distinto dispensado para as diferentes raças, visto que o mundo vivenciava o imperialismo e o neocolonialismo, as teses do darwinismo social, determinismo, racismo científico e eugenia constituíam o escopo para a conservação dessas violências.

O Conde de Gobideu, embaixador da França no Brasil e escritor do "Ensaio sobre a desigualdade das raças humanas", foi um dos observadores estrangeiros que apontaram os povos não-brancos e a miscigenação como os grandes problemas da nação, seus registros incluíam os seguintes insultos: macacos, malandros e criaturas particularmente repugnantes (RAEDERS, 1988 apud BOLSANELLO, 1996 ${ }^{1}$ ). Louis Agassiz ${ }^{2}$ também os identificou como "um tipo indefinido, híbrido, deficiente em energia física e mental" (SCHWARCZ, 2003). Na sociedade hodierna, tais estereótipos ainda marcam os negros e são insultos usados para invalidar essa parte da sociedade como merecedora de apreço e respeitabilidade social, inviabilizando sua participação política e acesso a oportunidades, ainda que nem sempre apareçam de forma direta. Naquela época foram usados para fomentar uma tese de embranquecimento da população brasileira. O pesquisador Antônio Sérgio Alfredo Guimarães em “Racismo e Anti-Racismo no Brasil” (1995) observa que cada racismo tem uma história específica e a teoria do embranquecimento é aquela que expõe o pensamento brasileiro.

\footnotetext{
"Embranquecimento" passou, portanto, a significar a capacidade da nação brasileira (definida como uma extensão da civilização européia, onde uma nova raça emergia) para absorver e integrar mestiços e pretos. Tal capacidade requer implicitamente a concordância das pessoas de cor em renegar sua ancestralidade africana ou indígena. "Embranquecimento" e "democracia racial" são pois conceitos de um novo discurso racialista(GUIMARÃES, 1995, p.39).
}

Assim, o discurso racial no Brasil foi pautado segundo essas ideias e principalmente a partir das publicações de Gilberto Freyre, sob o mito da cordialidade racial. Em virtude disso, a multietnicidade da população brasileira até a contemporaneidade é um obstáculo no reconhecimento da existência do racismo sistemático nessa sociedade. Contudo, os movimentos políticos antirracistas, após um longo processo de lutas, conquistaram legislações e políticas públicas, ainda que estas não sejam livres de falhas e careçam de efetividade em muitos âmbitos, são avanços imprescindíveis no combate ao racismo. Concomitantemente, a popularização do "politicamente correto" enquanto enfrentamento linguístico de expressões e ditos populares de origem preconceituosa revelou quão intrínseco era a prática racista corriqueira na sociedade brasileira.

${ }^{1}$ RAEDERS, George. O inimigo cordial do Brasil: o conde Gobineau no Brasil. Rio de Janeiro: Paz e Terra, 1998 apud BOLSANELLO, M. A. Darwinismo social, eugenia e racismo "científico": sua repercussão na sociedade e na educação brasileiras. In: Educar, n.12, p. 153-165. Curitiba: Editora da UFPR, 1996. Disponível em: < https://www.scielo.br/pdf/er/n12/n12a14.pdf> Acesso em 15 de outubro de 2020.

${ }^{2}$ GASSIZ, L., AGASSIZ, E. C. A Journey in Brazil. Boston: s. n., 1868 apud SCHWARCZ, LM. O espetáculo da miscigenação. In: DOMINGUES, HMB., SÁ, MR., and GLICK, T., orgs. A recepção do Darwinismo no Brasil. Rio de Janeiro: Editora FIOCRUZ, 2003, pp. 165-180. Disponível em: <http://books.scielo.org/id/txcs6/pdf/domingues-9788575414965-09.pdf> Acesso em 15 de outubro de 2020 . 
Durante a passagem dos anos 80 para 90, nos Estados Unidos da América, ativistas de esquerda trouxeram visibilidade à ideologia do "politicamente correto" enquanto estratégia política que enxergava a linguagem como possibilidade de transformação do tratamento social dirigido a grupos minoritários. Edwiges Morato e Anna Christina Bentes (2017), professoras do Departamento de Linguística do Instituto de Estudos da Linguagem (IEL) da Unicamp, ao analisarem alguns aspectos da trajetória do politicamente correto, utilizam a perspectiva de Stuart $\mathrm{Hall}^{3}$ como marco teórico para entender os objetivos desse conceito político:

Hall (1994) afirma que o politicamente correto traz em si um paradoxo: ele permitiria a emergência de lutas novas com armas antigas. As novas lutas sociais dizem respeito às lutas contra a invisibilidade de questões sociais tais como racismo, homofobia e machismo, trazendo à baila novas visões sobre gênero, sexualidade, etnicidade, etc. As armas antigas seriam justamente a atitude de policiamento da linguagem e a tentativa de substituição de um conjunto de verdades e identidades por outro conjunto de identidades e/ou verdades mais corretas. Para o autor, a proposta deveria ser a de desarranjar permanentemente todas as configurações de poder e, ao mesmo tempo, aceitar e negociar a diferença. (MORATO; BENTES, 2017, p. 16-17)

Assim, a ascensão desse movimento até o período hodierno e sua lenta, porém notável, adesão à política nacional brasileira culminou na censura social as formas diretas e tradicionais de preconceito, principalmente no meio acadêmico autor de produções científicas e no âmbito de instituições governamentais, mesmo que acompanhado de certa resistência da massa popular. Ao passo que aumentava a pressão em prol da condenação do racismo flagrante, as novas maneiras de discriminações veladas ganham cada vez mais espaço, dificultando a identificação e, consequentemente, punição desse tipo de conduta. Esta tese de mudança da visão social acerca dos modos tradicionais de racismo e surgimento de novas manifestações desse é apresentada no estudo “As novas formas de expressão do preconceito e do racismo" de LIMA e VALA (2004) ${ }^{4}$, no qual são analisadas as teorias trazidas pela psicologia social após a Segunda Guerra Mundial, o grande marco histórico de barbáries contra minorias e exposição em nível global dos preconceitos sociais vigentes. Dentre as diversas teorias criadas, neste trabalho serão apresentadas apenas as do Racismo Moderno (de J. B. McConahay), dos Preconceitos Sutil e Flagrante (de Pettigrew e Meertens) e do Racismo Cordial (de Turra e Venturi).

\section{TEORIAS DE NOVOS RACISMOS}

${ }^{3}$ HALL, S. "Some 'Politically Incorrect' Pathways Through PC", in S. Dunant (ed.). The War of the Words: The Political Correctness Debate. London, Virago Press, 1994, pp. 164-84. apud MORATO, Edwiges. BENTES, Anna Christina. (2017). “O mundo tá chato": algumas notas sobre a dimensão sociocognitiva do politicamente correto na linguagem. Revista USP, (115), 1128. Disponível em: $<$ https://doi.org/10.11606/issn.2316-9036.v0i115p11-28>Acesso em 15 de outubro de 2020.

${ }^{4}$ Este trabalho é uma versão de um dos capítulos da Tese de Doutorado de Marcus Eugênio Oliveira Lima, sob a orientação do Professor Doutor Jorge Vala defendida em 2003. Jorge Vala é um dos expoentes da atualidade nesta temática, sendo o coautor das obras "Novos racismos: perspectivas comparativas" e "Expressões do racismo em Portugal". Suas pesquisas analisam uma série de novos conceitos de racismo oriundos de realidades sociais específicas com o fito de deslocá-las para perspectiva local portuguesa, neste trabalho tal metodologia contribuirá para traçar um percurso histórico dos estudos de novos racismos que resultaram na formação de concepções acerca da vivência brasileira, em especial aquelas teorias sobre o racismo cordial e recreativo. 
McConahay (1986) $)^{5}$ desenvolveu uma escala de medida para o que chamou de racismo moderno. Seu contexto de surgimento é referente aos EUA, uma sociedade bi-racial que passou por processos de segregação socioespacial baseada na discriminação racial e que adota a ascendência genealógica como critério de distinção entre brancos e não-brancos (povos afrodescendentes, latinos, amarelos e outros). Em virtude desses fatos, recentemente foram criadas Políticas de Ações Afirmativas (PAA) de reparação dessa situação a fim de concretizar uma igualdade material, a qual foi historicamente negligenciada. Todavia, após a aprovação das PAA foi verificada uma crescente discriminação velada, que partia do princípio de que todos são iguais, então negros e brancos têm acesso as mesmas oportunidades e as discriminações positivas feitas por essas políticas seriam um modo de privilegiar negros e prejudicar brancos. LIMA e VALA resumem a escala de McConahay como:

O racismo moderno se baseia no seguinte conjunto de crenças e avaliações: a) a discriminação é uma coisa do passado porque os negros podem agora competir e adquirirem as coisas que eles almejam; b) os negros estão subindo economicamente muito rápido e em setores nos quais não são bem-vindos; c) os meios e as demandas dos negros são inadequados ou injustos e, d) os ganhos recentes dos negros não são merecidos e as instituições sociais lhes dão mais atenção do que eles deveriam receber. (MCCONAHAY, 1986 apud LIMA e VALA, 2004, p. 404)

Em se tratando do Preconceito Sutil concebido por Pettigrew e Meertens (1995) ${ }^{6}$, oriundo da Europa, o grupo alvo são estrangeiros provenientes das antigas colônias europeias em fluxo migratório, mas seus conceitos principais podem ser extraídos para analisar a situação do racismo. Segundo LIMA e VALA, essa teoria consiste em distinguir dois tipos de preconceito: o flagrante (aberto, direto) e o sutil (distante, indireto). O primeiro acredita que esses grupos minoritários constituem uma ameaça político-econômica e por isso devem ser rejeitados do meio social e também interpessoal (não manter relações íntimas). Já o preconceito sutil salienta as diferenças culturais entre os grupos, crê que os membros do exogrupo não aderem aos valores tradicionais e por isso não ascendem socialmente, além de não expressar emoções positivas (simpatia, admiração) quanto a eles. Nesta tese, as ideias mais importantes para este artigo estão no tocante ao conformismo ou internalização de normas que punem somente o preconceito aberto, as antirracistas. Aqueles que as internalizam são os igualitários, que defendem a ampliação de direitos e acesso a oportunidades de minorias. Os sutis se conformam ou aceitam a norma, apesar dela não corresponder ao seu sistema de crenças, já o flagrante a rejeita e incide nela com suas condutas racistas diretas.

\footnotetext{
${ }^{5}$ McConahay, J. B. (1986). Modern racism, ambivalence, and the modern racism scale. In J. F. Dovidio \& S. L. Gaertner (Orgs.), Prejudice, discrimination, and racism (pp. 91-125). Nova York: Academic apud LIMA. Marcus Eugênio Oliveira, VALA, Jorge. As novas formas de expressão do preconceito e do racismo. In: Estudos de Psicologia 2004, 9(3), p. 401-411. Disponível em: $<$ https://www.scielo.br/pdf/epsic/v9n3/a02v09n3.pdf. $>$ Acesso em 15 de outubro de 2020.

${ }^{6}$ PETTIGREW, T. F., MEERTENS, R. W. (1995). Subtle and blatant prejudice in Western Europe. European Journal of Social Psychology, 25, 57-75 apud LIMA. Marcus Eugênio Oliveira, VALA, Jorge. As novas formas de expressão do preconceito e do racismo. In: Estudos de Psicologia 2004, 9(3), p. 401-411. Disponível em: < https://www.scielo.br/pdf/epsic/v9n3/a02v09n3.pdf.> Acesso em 15 de outubro de 2020.
} 


\begin{abstract}
A aceitação ou conformismo perante uma nova norma corresponde à sua adoção instrumental, por forma a garantir recompensas ou evitar punições, enquanto a internalização de uma nova norma ocorre quando existe congruência entre ela e o sistema de valores de um indivíduo. Repare-se que a norma anti-racista incide apenas sobre as expressões tradicionais do racismo. Assim, os indivíduos que rejeitam essa norma e não se inibem de exprimir publicamente crenças racistas abertas: as suas respostas são claramente antinormativas (racismo flagrante). Os indivíduos que aceitam ou se conformam à norma não exprimem o racismo tradicional, mas não se inibem de exprimir atitudes e crenças que não põem em causa essa norma (racismo subtil). Quanto àqueles que internalizaram a norma, fizeram-no no quadro de valores igualitários mais gerais e, neste sentido, as crenças que partilham estão para além da norma contra o racismo tradicional: não rejeitam apenas este tipo de racismo, mas rejeitam também as expressões novas que o racismo tende a assumir (igualitarismo). (BRITO; LOPES; VALA, 2015, p. 150-151)
\end{abstract}

Enquanto isso, o racismo cordial é essencialmente brasileiro. Em 1995 o Datafolha realizou uma pesquisa organizada por Cleusa Turra e Gustavo Venturi denominada "Racismo cordial: a mais completa análise sobre o preconceito de cor no Brasil" na qual consta o seguinte resultado: apenas 10\% dos brasileiros se auto identificam como racistas, todavia $87 \%$ desses mesmos entrevistados demonstraram preconceito em atitudes ou ao reproduzir/concordar com enunciados racistas (TURRA; VENTURI, 1995). O racismo cordial pode ser conceituado como um modo de discriminação contra negros, que se distingue dos outros por uma polidez superficial (ou cordialidade) que reveste atitudes e comportamentos discriminatórios, próprio das relações interpessoais e exteriorizado por meio do humor, expressões e ditos populares que reforçam estereótipos negativos sobre a população negra (LIMA; VALA, 2004)

\title{
4. RACISMO RECREATIVO
}

Todas essas teorias são de suma importância para a construção e compreensão do fenômeno a ser analisado em específico neste trabalho, o racismo recreativo. Este pode ser aqui entendido como uma espécie de racismo cordial manifestado especificamente pela forma de piadas ou representações humorísticas de cunho racial. Teorizada pelo jurista Adilson José Moreira em seu livro homônimo, esta tese tem como objetivo demonstrar o prejuízo trazido a população negra de modo geral pela reiteração de estereótipos racistas com o caráter "inofensivo" do humor. Moreira parte do princípio de que o racismo pode se revestir de distintos métodos em espaços geoculturais e contextos históricos diversos, adequando-se a realidade fática a fim de conservar as hierarquias raciais que socialmente rebaixa negros e ascende brancos.

Por causa da característica miscigenada do povo brasileiro e do racismo cordial que impera nas relações sociais, o racismo utiliza o tom jocoso característico dos diálogos brasileiros para incutir o projeto racial de dominação no imaginário popular de modo sutil, por meio do propósito de produzir o riso tão comum em falas cotidianas. A narrativa da cordialidade racial criou uma visão das relações sociais no Brasil que permite esse tipo de atitude e a desqualifica do caráter racista. É importante salientar que apesar do caráter velado deste método de racismo, sua sutileza não implica baixa frequência de manifestação. Ao contrário, é 
extremamente recorrente ouvir piadas ou ver representações racistas inclusive nas redes televisivas nacionais ${ }^{7}$. Em razão disso, o autor não minimiza o caráter perigoso do humor racista que é um ataque pessoal à honra, característica que confere respeitabilidade social a alguém, implicando em consequências não apenas morais como também econômicas ${ }^{8}$. Logo, reconhece-se o racismo recreativo como um projeto de dominação cuja definição implica em um tipo especial de opressão racial:

a circulação de imagens derrogatórias que expressam desprezo por minorias raciais na forma de humor, fator que compromete o status cultural e o status material dos membros desses grupos. Esse tipo de marginalização tem o mesmo objetivo de outras formas de racismo: legitimar hierarquias raciais presentes na sociedade brasileira de forma que oportunidades sociais permaneçam nas mãos de pessoas brancas. (MOREIRA, 2019, p. 24)

Os adjetivos usados de modo corriqueiro para ofender pessoas negras presentes desde as falas anteriormente citadas do Conde de Gobideu e de Louis Agassiz até as piadas atuais não são casuais, elas exprimem um sentido e objetivo específico. Moreira os explicada através das ideias da filósofa brasileira Gislene Aparecida dos Santos ${ }^{9}$ :

\begin{abstract}
Como afirma Gislene Aparecida dos Santos, a condição subordinada da população negra brasileira deve ser compreendida a partir das diversas políticas culturais que foram utilizadas para legitimar diferentes processos de marginalização racial. Entre elas estavam as noções da inferioridade moral e intelectual, de uma sexualidade degradada, da incapacidade de viverem dentro de uma sociedade organizada, da indolência constitutiva, da inferioridade estética, imagens que os aproximavam mais de animais do que de seres humanos. (MOREIRA, 2019, p. 64)
\end{abstract}

Portanto, todas essas imagens reforçadas sob forma de humor visam a marginalização de pessoas negras e seu afastamento de cargos de esfera pública, pois impossibilitam sua atuação efetiva no combate à desigualdade racial no país. Dessa forma, o ataque à honra subjetiva do indivíduo a quem é dirigido esses insultos é uma afronta a toda a comunidade negra da nação e deve ser coibida penalmente, uma vez que a impunidade comprova socialmente a validação dessa conduta que pode ser repetida sem que hajam consequências, incitando o ódio a minorias raciais e mantendo o racismo institucional presente nessa realidade.

Palavras comunicam valores culturais e não deixam de disseminar sentidos negativos devido a uma suposta ausência de motivação psicológica. Elas expressam um consenso

\footnotetext{
${ }^{7}$ Um dos exemplos citados por Moreira é o de Adelaide do programa "Zorra Total" (GLOBO) em que um homem é pintado de preto e caracterizado como uma pessoa pobre de modo pejorativo para fins humorísticos.

${ }^{8}$ Sobre os impactos materiais do racismo, é importante salientar que " $46,9 \%$ da população preta ou parda está na informalidade. O percentual entre brancos é 33,7\%. Um trabalhador branco recebeu, em média, $72,5 \%$ a mais do que um profissional preto ou pardo em 2017. Enquanto uma pessoa branca teve rendimento médio de R $\$ 2.615$ no ano passado, um negro (soma da população preta e parda) recebeu R \$ 1.516", conforme levantamento do IBGE analisado em reportagem do Carta Capital.

"SANTOS, Gislene Aparecida dos. A invenção do "ser negro": um percurso das idéias que naturalizaram a inferioridade dos negros. São Paulo: Educ/Pallas/FASEP, 2002, p.45-63 apud MOREIRA, Adilson José. Racismo Recreativo. São Paulo: Sueli Carneiro; Pólen, 2019, p. 64.
} 
social dos membros do grupo majoritário sobre o valor de pessoas que pertencem a minorias raciais. Por esse motivo, o sentido do humor racista deve ser interpretado dentro do contexto social no qual ele está inserido e não apenas como uma expressão cultural que objetiva produzir um efeito cômico. Piadas racistas só adquirem sentido dentro de uma situação marcada pela opressão e pela discriminação racial. (MOREIRA, 2019, p. 55)

Por essa conduta penalmente se referir ao crime de injúria racial, analisaremos esse tipo a seguir. Ao contextualizar essas teses sobre os novos racismos na experiência racial brasileira, é possível perceber elementos correspondentes que auxiliam na construção da alteridade (do ver o outro) no imaginário popular de modo a influenciar a posição da sociedade e suas instituições frente a situações de racismo. Este trabalho propõe-se a examinar especificamente as decisões judiciais referentes a injúria racial em caso de racismo recreativo. Tendo em vista que o Poder Judiciário é formado de indivíduos que possuem suas próprias crenças e valores pessoais, os quais refletem em sua interpretação jurídica e na aplicação da lei, é possível que o apagamento social das maneiras de racismo sutis impeça a devida punição deste no âmbito legal, especificamente na seara penal do tipo da injúria racial.

\section{AINJÚRIA RACIALNA DOUTRINA E NOS TRIBUNAIS DO BRASIL}

O delito de injúria está previsto no Código Penal no artigo 140: "Injuriar alguém, ofendendo-lhe a dignidade ou o decoro: Pena - detenção, de um a seis meses, ou multa”. Segundo Guilherme Nucci (2019) "injuriar significa ofender ou insultar [...]. No caso presente, isso não basta. É preciso que a ofensa atinja a dignidade (respeitabilidade ou amor-próprio) ou o decoro (correção moral ou compostura) de alguém", assim, aquele que atenta contra a autoestima alheia pratica crime amparado constitucionalmente no art.5, X, o qual garante a inviolabilidade à honra e a imagem da pessoa assegurando também direito a indenização pelo dano (BRASIL, 1988).

No entanto, o delito de injúria racial foi introduzido no ordenamento jurídico brasileiro por meio da lei $n^{\circ}$ 9.459/97, uma vez que a lei no 7.716/98, que tipifica o crime de racismo, prevê a presença de atos segregatícios para a configuração do delito, e neste caso, o que acontecia era a agressão verbal o que não se encaixava na referida norma, com isso o agressor era tipificado na injúria, a respeito da questão dispõe Japiassu(2018):

\footnotetext{
Era aquela "velha história": o réu alegava não ser racista, mas sim ter agido com raiva da vítima que, circunstancialmente, era de uma determinada raça ou cor. Sendo assim, os juízes tendiam a desclassificar o fato da Lei de Racismo para o crime de injúria simples do Código Penal. Por conta disso, entendeu o legislador de incluir o referido dispositivo no crime de injúria. A seu turno, a Lei $\mathrm{n}^{\circ}$ 10.471/2003 (Estatuto do Idoso) incluiu a pessoa idosa como vítima do presente injusto penal. (JAPIASSU, 2018, p. 1021)
}

Além da desclassificação para um crime menos gravoso o réu, muitas vezes, era absolvido com o argumento de mera exposição da liberdade de expressão, assim em consonância com Nucci: 
Aquele que, atualmente, dirige-se a uma pessoa de determinada raça, insultando-a com argumentos ou palavras de conteúdo pejorativo, responderá por injúria racial, não podendo alegar que houve uma injúria simples, e tampouco mera exposição do pensamento (como dizer que todo "judeu é corrupto" ou que "negros são desonestos"), uma vez que há limite para tal liberdade. Não se pode acolher a liberdade que fira direito alheio, que é, no caso, o direito à honra subjetiva. Do mesmo modo, quem simplesmente dirigir a terceiro, palavras referentes a "raça", "cor", "etnia", "religião" ou "origem", com o intuito de ofender, responderá por injúria racial ou qualificada. (NUCCI, 2019, p. 310)

Trata-se na verdade de uma qualificadora do crime de injúria, que eleva a pena do caput deixando de ser detenção, de um a seis meses, ou multa, passando a reclusão de um a três anos e multa, isso aliás é alvo de críticas por parte da doutrina, pois a pena do art. $140, \S 3^{\circ}$ é superior a vários outros delitos, a respeito disso assegura Luís Regis Prado: "verifica-se, porém, uma clara violação do princípio da proporcionalidade, visto que não houve a observância do justo equilíbrio que deve existir entre a gravidade do fato praticado e a sanção imposta". Assim como Damásio de Jesus e Cézar Roberto Bittencourt que afirmam existir ofensa ao princípio da proporcionalidade, pois trata-se de uma pena superior aos crimes de aborto, arts. 124 e 126, e homicídio culposo, art. 121, $\S 3^{\circ}$ do Código Penal. Discordando desse entendimento assevera Japiassu (2018):

Ressalte-se, por fim, que alguns consideram a pena da injúria preconceituosa elevada crítica esta que não se justifica. É preciso ter em conta a realidade cultural e social do Brasil, onde não pode ser valorado como fato de menor relevância e semelhante a qualquer injúria aquele que se apresenta como ofensa carregada de preconceito. A diversidade e as desigualdades materiais do País exigem tratamento diferenciado de injúria que é preconceituosa. (JAPIASSU, 2018, p. 1021)

Outra questão a respeito da injúria racial é a sua equiparação, ou não, na lei $n^{\circ} 7.716 / 89$, posto que o crime de racismo possui peculiaridades dadas pela Constituição Federal, sendo elas a imprescritibilidade e a inafiançabilidade. A doutrina se divide entre Cléber Masson, Cezar Roberto Bittencourt, Alexandre Salim, Rogério Sanches Cunha e Fernando Capez pois entendem que não é válida a equiparação dos crimes, por outro lado discordam desse entendimento Guilherme Nucci, Carlos Eduardo Japiassu e o próprio STJ, o qual já afirmou reiteradas vezes a imprescritibilidade do delito. ${ }^{10}$

Vale destacar que em muitos casos cabe perdão judicial aos crimes contra a honra, sendo que no caso

${ }^{10}$ PROCESSUAL PENAL. AGRAVO REGIMENTAL NO AGRAVO EM RECURSO ESPECIAL. TEMPESTIVIDADE COMPROVADA. AGRAVO CONHECIDO. INJÚRIA RACIAL. CRIME IMPRESCRITÍVEL. OFENSA A DISPOSITIVO CONSTITUCIONAL. IMPOSSIBILIDADE. USURPAÇÃO DE COMPETÊNCIA. MATÉRIA ANALISADA, EM CASO ANÁlOGO, PELO STF. AGRAVO REGIMENTAL PARCIALMENTE PROVIDO E INDEFERIDO O PEDIDO DE EXTINÇÃO DA PUNIBILIDADE. 1. Comprovada a republicação da decisão de inadmissão do recurso especial, é reconsiderada a decisão que julgou intempestivo o agravo. 2. Nos termos da orientação jurisprudencial desta Corte, com o advento da Lei n.9.459/97, introduzindo a denominada injúria racial, criou-se mais um delito no cenário do racismo, portanto, imprescritível, inafiançável e sujeito à pena de reclusão (AgRg no AREsp 686.965/DF, Rel. Ministro ERICSON MARANHO (DESEMBARGADOR CONVOCADO DO TJ/SP), SEXTA TURMA, julgado em 18/08/2015, DJe 31/08/2015). 3. A ofensa a dispositivo constitucional não pode ser examinada em recurso especial, uma vez que compete exclusivamente ao Supremo Tribunal Federal o exame de matéria constitucional, o qual já se manifestou, em caso análogo, refutando a violação do princípio da proporcionalidade da pena cominada ao delito de injúria racial. 4. Agravo regimental parcialmente provido para conhecer do agravo em recurso especial, mas negar-lhe provimento e indeferir o pedido de extinção da punibilidade. 
da injúria existe essa possibilidade, segundo o parágrafo $1^{\circ}$ quando há provocação da vítima ou a retorsão da ofensa, isto é, injúrias recíprocas, de acordo com o entendimento de SALIM e AZEVEDO:

\begin{abstract}
Perdão judicial: inadmissível no caso de injúria preconceituosa. Primeiro em face da posição topográfica do dispositivo $\left(\S 1^{\circ}\right)$, que vem antes da injúria qualificada $\left(\S 3^{\circ}\right)$. Se fosse a intenção do legislador aplicar o benefício à injúria preconceituosa, o perdão judicial deveria ser o último dos parágrafos do artigo 140. Depois, porque a promoção do bem de todos, sem preconceitos de origem, raça, sexo, cor, idade e quaisquer outras formas de discriminação é objetivo fundamental da República federativa do Brasil (art. $3^{\circ}$, IV, da CF/88), o que torna insustentável a aplicação do perdão judicial à hipótese. (SALIM;AZEVEDO, 2017, p. 197)
\end{abstract}

Em relação a consumação do crime de injúria por se tratar de crime formal, o crime é consumado a partir do momento que o sujeito passivo conhece a imputação ofensiva, independentemente de sentir ou não perturbação em sua honra subjetiva, sendo necessário somente que a conduta seja revestida de idoneidade ofensiva, de acordo com Fernando Capez. Além disso, consoante Bittencourt, não é necessário que a ofensa seja dirigida diretamente à vítima, podendo esta ter conhecimento por meio de terceiro ou através de correspondência ou envio de mensagens eletrônicas.

Ainda segundo alguns autores a injúria proferida em meio a uma discussão pode afastar o delito, por não haver o dolo específico (animus injuriandi), no entanto um ponto divergente entre a doutrina é a possibilidade do animus jocandi, isto é, ofensas pronunciadas em tom humorístico, serem ou não consideradas criminosas, a respeito dessa questão dispõe Capez:

segundo o entendimento majoritário da doutrina, é necessário, além do dolo, um fim especial de agir, consistente na vontade de ofender, denegrir a honra do ofendido - tratase do animus injuriandi. Inexiste o crime de injúria se o agente atua com animus jocandi, narrandi, consulendi, defendendi, corrigendi vel disciplinandi. (CAPEZ, 2019, p. 454)

Entretanto é necessário ressaltar que no Brasil é comum se utilizar do tom jocoso para manifestar ofensas raciais, tanto na forma verbal entre particulares como utilizando-se de personagens humorísticos que corroboram com estereótipos racistas, além disso, é possível que ao adotar tal discriminante o Poder Judiciário esteja corroborando para a impunidade do racismo recreativo ou até mesmo do bullying, dessa forma assegura NUCCI (2019):

Há entendimento predominante na doutrina e na jurisprudência pela não configuração do crime contra a honra, desde que o fato ofensivo ou o insulto seja proferido fora do contexto da específica vontade de conspurcar a reputação alheia ou o amor próprio da vítima. Estariam nesse âmbito as brincadeiras, embora de mau gosto, as narrativas reputadas como simples fofocas, os relatórios feitos em locais de trabalho, os depoimentos prestados em juízo emitindo opiniões, dentre outros. [...] Em poucas palavras, a ninguém é dado o direito de atingir a honra alheia, a pretexto de fazer pilhéria, narrar fato, corrigir ou aconselhar, e depois pretender que na sua conduta não havia o menor intuito de ofensa. No caso, o que deve ser considerado é o dano que a pessoa visada venha a sofrer". Mas esse elemento específico não consta da lei; advém da doutrina. Na lei, o dolo é genérico e pode-se macular a honra alheia inclusive por meio de dolo eventual. É preciso repensar a teoria do animus específico, já desatualizada no tempo. (NUCCI, 2019, p. 306-307) 
Ademais é comum o autor alegar ter relações cordiais com pessoas negras, ou que está acostumado a fazer "brincadeiras" desse tipo e por isso a sua intenção não foi gerar uma ofensa, tão pouco ser racista, sobre essa questão alude Adilson Moreira:

Esses atos caracterizados como brincadeiras entre pessoas adultas que não expressariam desprezo ou ódio racial reproduzem uma série de estereótipos raciais. Entretanto, verificamos que essas manifestações podem ser classificadas como injúrias porque comunicam hostilidade racial por meio do humor. (MOREIRA, 2019, p. 85)

É interessante observar que eventualmente o Poder Judiciário, imbuídos pelos argumentos outrora citados, não reconhece a injúria racial como uma conduta reprovável e passível de sanção estatal. Em sua obra Racismo Recreativo, Adilson Moreira fez um levantamento nos tribunais brasileiros e encontrou inúmeros casos em que o réu era absolvido invocando a tese falta de animus injuriandi. ${ }^{11}$ Outrossim, o Tribunal de Justiça do Rio de Janeiro desclassificou um caso de injúria racial alegando que meras brincadeiras não ofenderiam a vítima $^{12}$. Vale destacar que muitas vezes as ofensas ocorrem no ambiente laboral e acabam por absolvição devido a falta de elementos probatórios, dado que nesses casos só há prova testemunhal e normalmente colegas de trabalho negam o ocorrido ${ }^{13}$.

\footnotetext{
${ }^{11}$ BRASIL. Tribunal de Justiça de São Paulo, Apelação Criminal n. 327.399-3/5, Órgão Julgador: $3^{\text {a }}$ Câmara Criminal, Relator: Oliveira Ribeiro, 29 maio 2001 (classificando o uso do termo urubu para se referir a uma pessoa negra como um ultraje, mas insuficiente para caracterizar a intenção de ofender uma pessoa negra); BRASIL. Tribunal de Justiça de São Paulo, Apelação Criminal n. 9132135-76.2007.8.26.0000, Órgão Julgador: $8^{\text {a }}$ Câmara Criminal, Relator: Pedro de Alcântara, 15 ago. 1332012 (negando a existência da intenção de ofender a uma pessoa que teria dito para outra ficar de olho em um homem negro porque ele não gostava de trabalhar); BRASIL. Tribunal de Justiça de Minas Gerais, Apelação criminal n. 1.000.00.152296-0/000, órgão julgador: $3^{\text {a }}$ Câmara Criminal, Relator: Kelsen Carneiro (alegando que, apesar das provas que afirmaram a presença de brincadeiras de cunho racial, a parte não conseguiu comprovar a existência da intenção de ofensa racial); BRASIL. Tribunal de Justiça de Minas Gerais, Apelação Criminal n. 1.0000.00.152296-0/000, Órgão Julgador: $3^{\text {a }}$ Câmara Criminal, Relator: Kelsen Carneiro, 30 nov. 1999 (indeferindo recurso sob o argumento de que não o apelante não produziu provas de que as brincadeiras que faziam referência à raça do indivíduo como, por exemplo, "preto que nasceu bom, nasceu morto" tenham conotação racista); BRASIL. Tribunal de Justiça do Rio de Janeiro, Apelação Cível n. 2008.050.01548, Órgão Julgador: $1^{\text {a }}$ Câmara Cível, Relator: Antônio Jayme Boente, 2 abr. 2009 (absolvendo o acusado de injúria racial por acreditar que a expressão “Olha lá, a neguinha foi pra lá!”).

${ }^{12}$ BRASIL. Tribunal de Justiça do Rio de Janeiro, Apelação Cível n. 16893/2000, Órgão Julgador: 16 a Câmara Cível, Relator: Mario Roberto Mannheimer, 24 fev. 2005 (fazendo referência à imagem social da mulher negra como uma expressão de sua sexualidade); BRASIL. Segunda Vara do Trabalho de Contagem, Processo n. 01597- 2009-030-03-00-1, Juíza: Katia Fleury Costa Carvalho, 20 jun. 2010 (superior fazendo brincadeiras que continham ideias derrogatórias de uma funcionária por ser negra e por ser mulher); BRASIL. Tribunal Federal da $1^{\mathrm{a}}$ Região, Habeas Corpus n. 0011351-79.2017.4.02.0000, Órgão Julgador: Turma Especial Penal, Relator: Antônio Ivan Athié, 25 out. 2017 (concedendo habeas corpus porque não identificou intenção de ofender toda uma raça na frase "Pra ninguém achar que eu gosto só de loiras e ruivas deliciosas, minha negra ficou uma delícia. Eita negra cheirosa, gostosaaaa!!!!!!!! Eita lasqueira.”); BRASIL. Tribunal Regional do Trabalho da 1 ${ }^{\text {a }}$ Região, Recurso Ordinário n. 000034606.2010.5.01.0047, Órgão Julgador: $8^{\mathrm{a}}$ Turma, Relatora; Edith Maria Corrêa Tourinho, 30 ago. 2011 (empresa classificando comentários racistas e homofóbicos de um chefe em relação a um funcionário como meras brincadeiras que não poderiam ter ofendido o autor do processo).-15:RORSum 0010481-73.2019.5.15.0079 0010481-73.2019.5.15.0079 - Inteiro Teor"

${ }^{13}$ "Na inicial, a obreira relata que, a partir de novembro de 2017, passou a ser perseguida pelos colegas de trabalho, Nogueira, Andreza e Cleusa, sofrendo diariamente provocações na presença dos demais colegas (fl. 03). E, em 05/12/17, registrou Boletim de Ocorrência, pois aqueles colaboradores faziam piadas, como: "o hospital só tá contratando preto", "Se a energia acabasse ninguém iria enxergar a reclamante", "saci", "a declarante não tem cabelo", "a declarante parecia uma macaca" (fl. 03). Aduziu que, durante suas funções, Andreza dizia: "Não faz serviço de preto... faz bem feito" (fl. 03). Informa ter sofrido assédio moral sistemático e racial. A testemunha da ré disse nunca ter ouvido nem viu comentários racistas em relação à obreira, e que no setor existem outros empregados negros, não se recordando sobre a contratação de outras pessoas negras na época em que a reclamante foi contratada (fl. 207). [...] Como se vê, a testemunha da obreira não presenciou ninguém ofendendo diretamente a reclamante, sendo que a injúria descrita por ela, como fato único, decorre de percepção pessoal dos fatos presenciados, não se podendo aferir, com certeza, se as pessoas envolvidas estavam, de fato, se referindo à autora. [...] Portanto, não comprovados os fatos da exordial, improcedente o pedido de indenização por danos morais. [...] Nega-se provimento ao apelo. Tribunal Regional do Trabalho da $15^{\mathrm{a} R e g i a ̃ o ~ T R T-~}$ 15:RORSum 0010481-73.2019.5.15.0079 0010481-73.2019.5.15.0079 - Inteiro Teor”
} 
Além de não reconhecerem a prática do racismo recreativo como um hábito danoso, eventualmente, vê-se demonstrações evidentes de discriminação racial no âmbito do Judiciário. Neste ano, 2020, uma juíza do Estado do Paraná utilizou como critério de conduta social para aumentar a pena-base do réu a expressão "seguramente integrante do grupo criminoso, em razão da sua raça", este caso ganhou notoriedade midiática e foi levado até o Conselho Nacional de Justiça (CNJ):

\begin{abstract}
"Seguramente integrante do grupo criminoso, em razão da sua raça, agia de forma extremamente discreta os delitos e o seu comportamento, juntamente com os demais, causavam o desassossego e a desesperança da população, pelo que deve ser valorada negativamente (sic)", disse a sentença redigida pela juíza. (IBAHIA, 2020)
\end{abstract}

É valido destacar que o Poder Judiciário brasileiro, segundo dados do CNJ, é composto majoritariamente por pessoas brancas, fato comprovado pelo último Censo do Poder Judiciário realizado em 2013 pois mostrou que 15,6\% dos magistrados brasileiros eram negros, onde deste conjunto $14,2 \%$ se declaram pardos e 1,4\%, preto. A mesma pesquisa apontou que entre as mulheres magistradas, 1,5\% se considerava preta e $12,7 \%$, pardas, a falta de pessoas negras nesse espaço, pode explicar, embora não justifique, a inércia da Justiça diante de atos discriminatórios dessa natureza. Portanto, verifica-se que o humor racista, amplamente aceito socialmente, validado, em muitos casos, pela Justiça brasileira, é um reflexo do racismo enraizados nas estruturas sociais resultado de anos escravistas findados sem a devida reparação.

O desafio mais crítico para aqueles que lutam contra o racismo no Brasil está justamente em convencer a opinião pública do caráter sistemático e não-casual dessas desigualdades; mostrar a sua reprodução cotidiana através de empresas públicas e privadas, através de instituições da ordem pública (como a polícia e os sistemas judiciário e correcional); através das instituições educacionais e de saúde pública. Só assim pode-se esperar levantar o véu centenário que encobre as dicotomias elite/povo, branco/negro na sociedade brasileira. (GUIMARÃES, 1995, p. 43)

\title{
6.CONSIDERAÇÕES FINAIS
}

Ante o exposto ao longo deste trabalho, é possível perceber que a manifestação cotidiana do racismo é uma problemática estrutural na sociedade brasileira e como tal deve ser enfrentada em todas as suas facetas. Portanto, é aqui proposta a validação do enquadramento do racismo recreativo enquanto injúria racial como um instrumento na luta antirracista no país. Acerca dos crimes de injúria racial e de racismo, é possível retomar a teoria de Pettigrew e Meertens sobre as normas antirracistas que somente coíbem o racismo flagrante. A injúria racial foi criada exatamente para contornar a impunidade que estava ocorrendo com a desclassificação do crime de racismo (norma antirracista destinada a punir de maneira mais gravosa apenas sobre as expressões tradicionais do racismo) para o crime de injúria (menor potencial ofensivo visando ofensas à honra subjetiva de modo geral). Ao sancionar a qualificadora da injúria racial restou a comprovação de que havia no Brasil um método de racismo sutil que a Lei $n^{0} 7.716 / 98$ não era capaz de punir. Assim, era almejado que com essa modalidade mais gravosa de injúria, essa conjuntura fosse transformada. 
Entretanto, a maior parte dos profissionais do direito, tanto doutrinadores como julgadores e advogados, entenderam que a norma só poderia incidir em casos de formas tradicionais do racismo direto, exigindo assim o elemento subjetivo do dolo específico, o animus injuriandi. Destarte, criou-se mais uma norma que só poderia ser aplicada ao racismo aberto, direto e evidente. O óbice deste caso está no uso de uma hermenêutica excludente, que não enxerga a evolução de um problema social no contexto da realidade local. Para tratar de racismo no Brasil, é imprescindível trazer à baila o mito da democracia racial e da cordialidade que impede o reconhecimento da existência do racismo fora do âmbito casual do alvo dessas "brincadeiras" ser recorrentemente negro e para isso o Judiciário brasileiro não pode se mostrar inerte.

A exigência de um dolo específico de injuriar não enxerga que o humor racista não é apenas resultado do psiquismo do autor, mas reproduções de ideias pejorativas presentes no contexto social. Embora a mera existência desse tipo penal comprove a preocupação legislativa dos representantes do povo em coibir ofensas racistas e mudar as ideias preconceituosas sob as quais este país foi fundado, por intervenção do poder de punir do Estado. Logo, não é lógico que o indivíduo ofendido tenha sua respeitabilidade social ofendida, recorra a medida drástica de provocar a seara penal (ultima ratio da sociedade) e tenha sua demanda negada em razão de uma construção doutrinária que cega os olhos para a realidade social.

Negar a população negra brasileira o direito de ter sua honra protegida seria encobrir um racismo moderno que se baseia na crença de que as demandas sociais dos negros são injustas e que as instituições legais não deveriam lhes dispensar atenção, conforme a escala de McConahay. É preciso compreender que o racismo institucional não se manifesta somente com a atuação positiva do Estado contra pessoas negras, escravizando-as, aprisionando-as ou matando-as. Ele também se revela com a omissão e a indiferença social em face de um problema que afeta grande parte dos habitantes do Brasil. As decisões judiciais que não aceitam o enquadramento do racismo recreativo no tipo da injúria penal constituem um tipo de agressão institucional e enquanto para os julgadores é apenas uma sentença, para o indivíduo atingido isso significa descrédito nas instituições jurídicas e a manutenção de uma democracia só ocorre mediante a confiança do povo nas instituições que os representam para a defesa de seus interesses. Portanto, este problema, como outros perceptíveis na sociedade, deve ser observado de maneira ampla, analisando os impactos micro e macro sociais a curto e longo prazo.

\section{REFERÊNCIAS BIBLIOGRÁFICAS:}

\section{BITENCOURT, Cezar Roberto. Parte especial: crimes contra a pessoa. Coleção Tratado de direito penal.} volume 2, 20a . ed. São Paulo, Saraiva Educação, 2020.

BOLSANELLO, M. A. Darwinismo social, eugenia e racismo "científico": sua repercussão na sociedade e na educação brasileiras. In: Educar, n.12, p. 153-165. Curitiba: Editora da UFPR, 1996. Disponível em: $<$ https://www.scielo.br/pdf/er/n12/n12a14.pdf $>$ Acesso em 15 de outubro de 2020. 
BRASIL. Constituição da República Federativa do Brasil de 1988. Disponível em: $<$ http://www.planalto.gov.br>Acesso em 12 de out. 2020.

BRASIL. Decreto-lei no 2.848, de 7 de dezembro de 1940. Código Penal. Disponível em: $<$ http://www.planalto.gov.br/ccivil_03/Decreto-lei/Del2848compilado.htm>Acesso em: 12 de out. 2020..

CAPEZ, Fernando. Curso de Direito Penal, volume 2, parte especial: arts. 121 a 212. 19ª ed. atual. São Paulo, Saraiva Educação, 2019.

CARTA CAPITAL. Um em cada dois negros está no mercado informal. E vai piorar. Disponível em: $<$ https://www.cartacapital.com.br/economia/um-em-cada-dois-negros-esta-no-mercado-informal-e-vaipiorar/> Acesso em 15 de outubro de 2020.

CUNHA, Rogério Sanches. Manual de Direito Penal: parte especial (arts. 121 ao 361). $1^{\mathrm{a}}$ ed. rev., ampl. e atual. Salvador: JusPODIVM, 2018.

GUIMARÃES, Antonio Sérgio Alfredo. Racismo e Anti-Racismo no Brasil. In: Novos Estudos CEBRAP N. ${ }^{\circ} 4 \mathbf{3}, \quad$ n o v e m b r o 1995 p p. $26-44$. D i s p o n ív e 1 e m : $<$ https://edisciplinas.usp.br/pluginfile.php/2128310/mod_resource/content/1/ASG_racismo_e_anti_racism o_NE\%2043_1995.pdf> Acesso em 15 de outubro de 2020.

IBAHIA. Juíza cita cor da pele do réu ao condená-lo: 'em razão da sua raça'. 12/08/2020 às 12 h02, disponível em: <https://www.ibahia.com/brasil/detalhe/noticia/juiza-cita-cor-da-pele-do-reu-ao-condenalo-em-razao-da-sua-raca/> Acesso em 15 de outubro de 2020

JESUS, Damásio de. Parte especial: crimes contra a pessoa a crimes contra o patrimônio arts. 121 a 183 do CP; atualização André Estefam. Direito penal vol. 2.36a . ed. São Paulo, Saraiva Educação, 2020.

LIMA. Marcus Eugênio Oliveira, VALA, Jorge. As novas formas de expressão do preconceito e do racismo. In: Estudos de Psicologia 2004, 9(3), p. 401-411. Disponível em: $<$ https://www.scielo.br/pdf/epsic/v9n3/a02v09n3.pdf. > Acesso em 15 de outubro de 2020

MASSON, Cleber. Direito penal: parte especial: arts. 121 a 212. $11^{\mathrm{a}}$ ed. rev., atual. e ampl. Rio de Janeiro, Forense, São Paulo. MÉTODO, 2018.

MORATO, Edwiges. BENTES, Anna Christina. (2017). "O mundo tá chato": algumas notas sobre a dimensão sociocognitiva do politicamente correto na linguagem. In: Revista USP, (115), 11-28. Disponível em: $<$ https://doi.org/10.11606/issn.2316-9036.v0i115p11-28> Acesso em 15 de outubro de 2020.

NUCCI, Guilherme de Souza. Curso de Direito Penal: parte especial: arts. 121 a 212 do Código Penal. $3^{\text {a }}$. ed. Rio de Janeiro, Forense, 2019.

PRADO, Luiz Regis. Tratado de Direito Penal: parte especial - arts.121 a 249 do CP, volume 2. $3^{\text {a }}$. ed. Rio de Janeiro, Forense, 2019. 
SALIM, Alexandre. AZEVEDO, Marcelo A. d. Direito Penal: parte especial- dos crimes contra pessoa aos crimes contra a família. $6^{\mathrm{a}}$ ed. rev., ampl. e atual. Salvador: JusPODIVM, 2017.

SCHWARCZ, LM. O espetáculo da miscigenação. In: DOMINGUES, HMB., SÁ, MR., GLICK, T., orgs. A recepção do Darwinismo no Brasil. Rio de Janeiro: Editora FIOCRUZ, 2003, pp. 165-180. Disponível em: $<$ http://books.scielo.org/id/txcs6/pdf/domingues-9788575414965-09.pdf $>$ Acesso em 15 de outubro de 2020.

SOUZA, Artur de B. G. JAPIASSU, Carlos E. A. Direito penal: volume único. São Paulo, Atlas, 2018.

STJ. Agravo Regimental no Agravo em Recurso Especial. AgR em AgRE 686.965/DF, Rel. Ministro ERICSON MARANHO, SEXTA TURMA, DJe 31/08/2015. Disponível em: $<$ https://scon.stj.jus.br/SCON/pesquisar.jsp>Acesso em 10 de out. 2020.

TJRJ. Apelação Cível n. 16893/2000, Relator: Mario Roberto Mannheimer, DJ: 24 fev. 2005. JusBrasil, 2020 .

$<$ https://www.jusbrasil.com.br/jurisprudencia/busca?q=inj\%C3\%BAria+racial+absolvi\%C3\%A7\%C3\%A $30 \& p=2>$ Acesso em 10 de out. 2020.

TJSP. Apelação Criminal n. 327.399-3/5, Relator: Oliveira Ribeiro, DJ: 29 maio 2001. JusBrasil, 2020. Disponível em: $<$ https://www.jusbrasil.com.br/jurisprudencia/busca?q=inj\%C3\%BAria+racial $>$ Acesso em 10 de out. 2020.

TRT-15. Recurso Ordinário: RORs 0010481-73.2019.5.15.007900010481-73. Relator: Maurício de A $1 \mathrm{me}$ ida, Inteiro Teor, D J : 04 de mai. 2020 . Disponíve 1 e m : $<$ https://rt-15.jusbrasil.com.br/jurisprudencia/853419410/rorsum-104817320195150079-00104817320195150079/inteiro-teor-853419420?ref=serp> Acesso em 10 de out. 2020. 